Discussion Paper No. 01-45

Green Tax Reform and Employment: The Interaction of Profit and Factor Taxes

Stefan Boeters

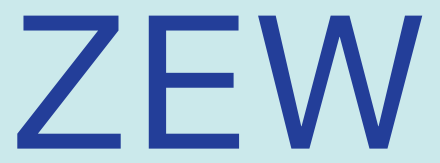

Zentrum für Europäische Wirtschaftsforschung GmbH

Centre for European Economic Research 

Discussion Paper No. 01-45

\title{
Green Tax Reform and Employment: The Interaction of Profit and Factor Taxes
}

\author{
Stefan Boeters
}

Download this and other ZEW Discussion Papers from our ftp server:

ftp://ftp.zew.de/pub/zew-docs/dp/dp0146.pdf

Die Discussion Papers dienen einer möglichst schnellen Verbreitung von neueren Forschungsarbeiten des ZEW. Die Beiträge liegen in alleiniger Verantwortung der Autoren und stellen nicht notwendigerweise die Meinung des ZEW dar.

Discussion Papers are intended to make results of ZEW research promptly available to other economists in order to encourage discussion and suggestions for revisions. The authors are solely responsible for the contents which do not necessarily represent the opinion of the ZEW. 



\section{Non-Technical Summary}

For the political prospects of any kind of ecological tax reform (higher energy tax, lower labour tax) it is crucial to know whether a "double dividend" should be expected, i.e. whether there are economic benefits of this reform other than the ecological effect. With persistent unemployment in most European countries, the second dividend could be most desirable on the labour market. Consequently, there is a large volume of economic literature that analyses under what conditions a rise in the energy tax has positive employment effects.

This paper shows that the scope for a employment-enhancing tax reform depends on the presence of after-tax profits and their taxation. The share of profits and the level of the profit tax determine a critical level for the energy tax rate. As long as the latter is below this level, a green tax reform can boost employment. However, when the critical level has been surpassed, the employment effects will be negative.

This finding about the upper bound for an employment-enhancing tax reform is fairly robust when we move from a labour market with unemployment to a competitive one. In comparison, any proposition about the desirable ratio between energy and labour tax rate will be highly sensitive to changes in the assumptions about the basic mechanism on the labour market.

The most promising strategy for assessing the labour market effects of an ecological tax reform therefore seems to be to concentrate on the critical level of the energy tax and its key determinants. The comparison of energy and labour tax rates is a less reliable procedure. 



\title{
Green Tax Reform and Employment: The Interaction of Profit and Factor Taxes
}

\author{
Stefan Boeters* \\ Centre for European Economic Research
}

April 2001

\begin{abstract}
The employment effects of an ecological tax reform depend decisively on the presence of a profit tax and on the extent to which profits are taxed. This is shown in a model where firms have monopoly power on product markets and bargain over wages with unions on the labour market. In this setting, the value of the employment-maximising energy tax rate depends on the level of the profit tax. The question of whether there is unemployment or not turns out to be less important.
\end{abstract}

Keywords: factor taxes, profit taxes, ecological tax reform, trade unions, unemployment

JEL Code: H 20, J 51

${ }^{*}$ Centre for European Economic Research, Environmental and Ressource Economics, P.O. Box 1034 43, 68034 Mannheim, Germany, E-Mail: boeters@zew.de. I am grateful to Wolfram Richter, Kerstin Schneider, Ronnie Schöb and Christian Keuschnigg for helpful suggestions. 


\section{Introduction}

The theoretical as well as much of the political discussion about ecological tax reforms has been dominated by the question of a possible "double dividend". While the first dividend is generally taken for granted in terms of better environmental quality, the political prospects of actual tax reform proposals depend to a high extent on whether there are further benefits to be reaped. Since unemployment remains the outstanding economic problem in most European countries, it is especially tempting to look for the second dividend on the labour market and ask whether employment can be boosted by a revenue-neutral tax reform. This question was first analysed in models with competitive labour markets, but the focus of the double dividend literature shifted to the explicit consideration of labour market imperfections. The results are mixed, but if a positive employment dividend can be reported at all, it tends to depend on very special conditions (see, e.g., Bovenberg/van der Ploeg 1994, Schneider 1997, Scholz 1998, Richter/Schneider 2001).

More recently, however, papers by Koskela/Schöb/Sinn (1998, 2001), Marsiliani/Renström (2000) and Michaelis/Pflüger (2000) appear to produce surprisingly robust results in favour of positive employment effects of an ecological tax reform. These papers have in common that unemployment results from union power and firms sell their output on imperfectly competitive markets. They all come to the conclusion that there are positive employment effects of ecological tax reforms as long as the initial level of the energy tax (the tax on the polluting input factor) is low.

Of the three approaches mentioned, I take the first one, Koskela/Schöb/Sinn (1998, 2001, to be referred to as "KSS"), as my point of reference. It is the simplest one, but it still contains all the essential features that are needed to carry out a 
general equilibrium analysis with unemployment. Although they share the same basic structure with the KSS approach, Marsiliani/Renström (2000) is considerably complicated by domestic demand effects, and Michaelis/Pflüger (2000) focus on an elaborated payment balance mechanism.

The key insight of the KSS papers ${ }^{1}(1998,2001)$ is that, with a fixed net of tax wage, positive employment effects occur as a result of a revenue-neutral tax reform as long as the initial energy tax rate is lower than the wage tax rate. Such a fixed net wage can be generated by the assumption of Cobb-Douglas production, combined with a firm-union wage bargaining setting. If production is of the CES type, there is an additional effect that depends on the elasticity of substitution between energy and labour. KSS (1998) show that, with an elasticity of substitution exceeding unity, the net wage decreases as a result of the tax reform, and the employment boosting effect is even enlarged. If, on the other hand, the elasticity of substitution falls short of unity, the tax reform causes wages to rise and the employment effect is ambiguous. Nevertheless, for realistic parameter values, a strong case for positive employment effects seems to remain.

In this paper I show that the labour market effects of tax reforms depends crucially on the presence of after-tax profits. By introducing a tax on profits and letting its rate approach 100 per cent, one can make the scope for an employment enhancing green tax reform disappear. When profits are completely taxed away, we end up in a situation where positive factor taxes become altogether Laffer-inefficient. The indirect losses in tax revenue from the profit tax will always outweigh the revenue from a tax on one of the variable factors of production.

To put these findings in perspective, I compare the model with wage bargaining

\footnotetext{
${ }^{1}$ Koskela/Schöb (1998) make an analogous point with respect to capital taxation.
} 
to a model where firms have monopoly power on the output market but competition prevails on the labour market. It can then be seen that the value of the profit tax has a direct impact on the scope for employment enhancing tax reforms, independent of whether or not there is unemployment. In contrast to the case of wage bargaining, small positive wage tax rates are Laffer-efficient when the labour market is competitive.

The remainder of the paper is organised as follows. The basic features of the wage bargaining model are presented in Sections 2 and 3. Profit taxes are introduced in Sections 4 (rigid wage) and 5 (variable wage). In Section 6, I compare the results with the case of a competitive labour market. Section 7 concludes.

\section{Basic elements of wage bargaining model}

There are two factors of production, labour, $L$, and energy, $R$. Output, $Y$, is produced by a representative firm with a CES-technology ${ }^{2}$

$$
Y=Y(L, R)=\left[L^{(\sigma-1) / \sigma}+R^{(\sigma-1) / \sigma}\right]^{\sigma /(\sigma-1)},
$$

with $\sigma$ denoting the elasticity of substitution. Output is sold on international markets with exogenous, iso-elastic demand curves,

$$
Y=p^{-\varepsilon} \text {. }
$$

\footnotetext{
${ }^{2}$ The model of this section closely follows Koskela/Schöb/Sinn $(1998,2001)$. The main differences between the 1998 and the 2001 paper are: (i) In KSS (1998) there is monopolistic competition among individual firms on the product market, and wages are bargained over at the firm level. By contrast, KSS (2001) assume perfect competition between firms and a iso-elastic demand curve for the whole economy. (ii) KSS (1998) cover the case of wage bargaining under CES production, whereas KSS (2001) focus on a fixed net wage. This is the outcome in KSS's (1998) special case of $\mathrm{CD}$ production.
} 
$\varepsilon$ is the elasticity of output demand, exceeding unity to guarantee a profit maximum. Profit can be calculated as revenues less gross factor payments

$$
\pi=p Y-\tilde{w} L-\tilde{q} R
$$

Gross factor prices are $\tilde{w}=\left(1+t_{w}\right) w$ and $\tilde{q}=\left(1+t_{q}\right) q$, where the net price of energy, $q$, is internationally given and the net wage, $w$, is the result of a bargaining process between the firm and a union. $t_{w}$ and $t_{q}$ denote the wage tax and the energy tax, respectively.

Profit maximization yields conditional factor demand functions, $L=L(\tilde{w}, \tilde{q})$, $R=R(\tilde{w}, \tilde{q})$, and the price setting rule, $p\left(1-\varepsilon^{-1}\right)=c(\tilde{w}, \tilde{q})$, where $c$ is the unit cost function.

On the labour market, the trade union and the firm bargain over wages. The objective function of the trade union is assumed to be

$$
V=w L+b(N-L)
$$

$N$ denotes the total labour force and $b$ is the unemployment benefit, both exogenous. The fall-back position of the union is given by $V^{0}=b N$ and the wage, $w$, is derived by maximising the Nash product

$$
\Omega=\left(V-V^{0}\right)^{\beta} \pi^{1-\beta},
$$

where $\beta$ measures the bargaining power of the union. The properties of this bargaining system are analysed in KSS (1998), and in the following I will draw on the results of that paper. 


\section{A graphical representation of tax reforms}

Let us first assume that tax revenue is only generated by taxes on the two factors of production. The government budget, $G$, then reads ${ }^{3}$

$$
G=t_{w} w L+t_{q} q R
$$

Alternatively, this can be written as the value of total production less net factor payments and profits

$$
G=p Y-w L-q R-\pi
$$

With iso-elastic output demand, $\pi$ amounts to a fixed proportion, $\varepsilon^{-1}$, of sales revenues, and (2) can be rewritten as

$$
G=\kappa Y^{\kappa}-w L-q R
$$

where $\kappa=1-\varepsilon^{-1}$ is the share of gross factor payments in sales revenues.

To get a clear picture of how tax changes affect the budget, let us focus in this section on the case of Cobb-Douglas production. In this variant of the model, the net wage as the outcome of the firm-union bargaining is independent of the tax rates ${ }^{4}$. For the analysis of the government's tax decisions, the only remaining arguments of the factor demand functions are the tax rates themselves: $L=L\left(t_{w}, t_{q}\right), R=$

\footnotetext{
${ }^{3}$ To be able to compare the results with KSS's, I follow their approach of focussing on tax revenues gross of unemployment benefit payments. This matters for the determination of revenue neutral tax reforms, which might alternatively be defined by fixing tax revenues net of unemployment benefit payments.

${ }^{4}$ This is shown in KSS (1998). The model then coincides with KSS (2001) and other papers where a fixed net wage is assumed to generate unemployment (Bovenberg/van der Ploeg 1996, Bovenberg/van der Ploeg 1998a).
} 
$R\left(t_{w}, t_{q}\right)$. Written in functional form, the budget then is

$$
G\left(t_{w}, t_{q}\right)=\kappa Y^{\kappa}\left[L\left(t_{w}, t_{q}\right), R\left(t_{w}, t_{q}\right)\right]-w L\left(t_{w}, t_{q}\right)-q R\left(t_{w}, t_{q}\right)
$$

and the overall revenue effect of a rise in either of the taxes can be given as

$$
\begin{aligned}
G_{t_{w}} & =\left(\kappa^{2} p Y_{L}-w\right) L_{t_{w}}+\left(\kappa^{2} p Y_{R}-q\right) R_{t_{w}} \\
G_{t_{q}} & =\left(\kappa^{2} p Y_{L}-w\right) L_{t_{q}}+\left(\kappa^{2} p Y_{R}-q\right) R_{t_{q}}
\end{aligned}
$$

where subscripts denote partial derivatives. Using the first order conditions of profit maximisation, $\kappa p Y_{L}=\tilde{w}$ and $\kappa p Y_{R}=\tilde{q}$, this can be written as

$$
\begin{aligned}
G_{t_{w}} & =\tilde{t}_{w} w L_{t_{w}}+\tilde{t}_{q} q R_{t_{w}} \\
G_{t_{q}} & =\tilde{t}_{w} w L_{t_{q}}+\tilde{t}_{q} q R_{t_{q}}
\end{aligned}
$$

with $\tilde{t}_{i}=\left[\kappa\left(1+t_{i}\right)-1\right]=t_{i}-\left(1+t_{i}\right) \varepsilon^{-1}(i=w, q)$. These derived tax rates, $\tilde{t}_{w}$ and $\tilde{t}_{q}$, will be used to characterise the consequences of tax reforms with different starting points. Note that $\tilde{t}_{i}$ varies monotonously with $t_{i}$ and is always smaller than the latter. Fig. 1 depicts the space of possible tax-rate combinations ("tax structures") to form a background for the discussion of tax reforms.

- Fig. 1 about here -

An important point of reference is the tax structure that generates the highest possible overall tax revenue. This is the case at point $\mathbf{M}$ in Fig. 1 where the tax rates are such that they maximise $G\left(t_{w}, t_{q}\right)$, as given by $(3)$, in $t_{w}$ and $t_{q}$. The firstoder conditions of this problem are $G_{t_{w}}=G_{t_{q}}=0$, and this implies $\tilde{t}_{w}=\tilde{t}_{q}=0$, or

$$
\frac{t_{q}}{1+t_{q}}=\frac{t_{w}}{1+t_{w}}=\frac{1}{\varepsilon}
$$


because $L_{t_{w}} R_{t_{q}}-L_{t_{q}} R_{t_{w}}>0 .{ }^{5}$ The revenue maximising tax structure, $\mathbf{M}$, is just at the intersection of the two curves of partial revenue maxima, $\bar{t}_{w}$ and $\bar{t}_{q}$. The line $\bar{t}_{w}\left(t_{q}\right)$ depicts the solutions to partially maximising $G\left(t_{w}, t_{q}\right)$ in $t_{w}$ for given $t_{q}$. $\bar{t}_{w}$ has a negative slope because the lower $t_{q}$, the lower are the negative revenue effects of a rise in $t_{w}$ through a reduced use of energy. In the same manner, $\bar{t}_{q}\left(t_{w}\right)$ is determined by maximising $G\left(t_{w}, t_{q}\right)$ in $t_{q}$ for given $t_{w} . \bar{t}_{q}$ is flatter than $\bar{t}_{w}$ and intersects $\bar{t}_{w}$ at $\mathbf{M}$. Thus, in the shaded region both tax rates are Laffer-efficient ${ }^{6}$. The tax structures in this region will be called "efficient" tax structures ${ }^{7}$.

This region can be divided into three subregions by two salient lines, LM and YM. First consider the case that employment is to be maximised for a given tax revenue. The line $\mathbf{L M}$ is derived by varying $\bar{g}$ and by solving $\max L\left(t_{w}, t_{q}\right)$ s.t. $G\left(t_{w}, t_{q}\right)=\bar{g} \cdot{ }^{8}$ In this case the marginal employment losses per unit of additional revenue are the same for both taxes. The employment maximising tax structures

${ }^{5}$ This directly follows from $\eta_{L, \tilde{w}} \eta_{R, \tilde{q}}-\eta_{R, \tilde{w}} \eta_{L, \tilde{q}}>0$ where $\eta_{x, y}$ denotes the elasticity of variable $x$ with respect to $y$ :

$$
\begin{array}{ll}
\eta_{L, \tilde{w}}=\frac{d L}{d\left(\left(1+t_{w}\right) w\right)} \frac{\left(1+t_{w}\right) w}{L}=(\sigma-\varepsilon) s-\sigma, & \eta_{L, \tilde{q}}=\frac{d L}{d\left(\left(1+t_{q}\right) q\right)} \frac{\left(1+t_{q}\right) q}{L}=(\sigma-\varepsilon)(1-s), \\
\eta_{R, \tilde{w}}=\frac{d R}{d\left(\left(1+t_{w}\right) w\right)} \frac{\left(1+t_{w}\right) w}{R}=(\sigma-\varepsilon) s, & \eta_{R, \tilde{q}}=\frac{d r}{d\left(\left(1+t_{q}\right) q\right)} \frac{\left(1+t_{q}\right) q}{R}=(\sigma-\varepsilon)(1-s)-\sigma,
\end{array}
$$

where $s$ is the factor share of labour in total factor payments: $s=\tilde{w} L /\left(\kappa Y^{\kappa}\right)$.

6 "Laffer efficiency" in the context of this model is to be understood with respect to the tax system as a whole: A rise in a Laffer-efficient tax increases overall tax revenue.

${ }^{7}$ This means, "efficiency" of tax structures solely refers to the capacity of the taxes to generate additional revenue. There are no welfare implications intended.

${ }^{8}$ The determination of $\mathbf{L M}$ is for positive, not for normative, purposes. It serves to deliminate tax reforms with a positive employment effects from those with a negative employment effect. The model is not sufficiently specified to carry out a welfare analysis. But there is a possible specification that links welfare directly to employment: Assume that the firms are owned by foreigners and the marginal disutiliy of labour is below the wage as long as there is unemployment. 
thus solve:

$$
\frac{L_{t_{w}}}{G_{t_{w}}}=\frac{L_{t_{q}}}{G_{t_{q}}}
$$

which, by (4) and (5), simplifies to $\tilde{t}_{q}=0$ or

$$
\frac{t_{q}}{1+t_{q}}=\frac{1}{\varepsilon}
$$

That means the employment maximising energy tax rate equals the revenue maximising rate. This is represented in Fig. 1 by a horizontal LM curve. Analogously, we can characterise tax structures that maximise $Y\left(L\left(t_{w}, t_{q}\right), R\left(t_{w}, t_{q}\right)\right)$ s.t. $G\left(t_{w}, t_{q}\right)=\bar{g}^{9}$ for a varying exogenous tax revenue, $\bar{g}$, by

$$
\frac{Y_{L} L_{t_{w}}+Y_{R} R_{t_{w}}}{G_{t_{w}}}=\frac{Y_{L} L_{t_{q}}+Y_{R} R_{t_{q}}}{G_{t_{q}}}
$$

which results in the simple condition $t_{w}=t_{q}$ depicted by the line YM. Finally, there are iso-revenue curves like the line abcd for an arbitrarily chosen value of $\bar{g}$. A revenue-neutral tax reform is represented by a move along that line. The tax reform is an ecological one if $t_{q}$ is raised, that is, if we move in the direction of the arrow on the line abcd. We can distinguish three different cases: (i) both employment and output increase (between $\mathbf{a}$ and $\mathbf{b}$ ), (ii) employment increases but output goes down (between $\mathbf{b}$ and $\mathbf{c}$ ) and (iii) both employment and output decreases (between c and $\mathbf{d})^{10}$. Fig. 1 thus reproduces graphically KSS's results that

\footnotetext{
${ }^{9}$ Again, this does not have normative implications, but only serves to distinguish tax reforms with different consequences for observable economic variables. In KSS (2001), however, the output level has been highlighted as a measure for international competitiveness.

${ }^{10}$ In principle, we could even go beyond $\mathbf{d}$. As the main reason for levying $t_{q}$ is an ecological one, Laffer-inefficient values of $t_{q}$ (above $\bar{t}_{q}$ ) might well be acceptable if they are justified by ecological considerations. But note that in the case of a Laffer-inefficient $t_{q}$ the tax reform is not of the form that normally underlies policy proposals. Increasing $t_{q}$ then would mean a loss of tax revenue,
} 
1. there is scope for an employment enhancing, revenue neutral tax reform ("double dividend") and

2. the employment gain is guaranteed as long as $t_{w}>t_{q}$.

\section{Introduction of a profit tax}

In Section 3, as in KSS $(1998,2001)$, only the two taxes on the factors of production, $t_{w}$ and $t_{q}$, were available. There are several reasons for introducing an additional tax on profits. Besides the small gain in realism, this allows us to better relate the model to the existing literature. In models featuring positive profits, it is often assumed that these profits are fully taxed away (compare the similar settings of Fuest/Huber 1998 and Boeters/Schneider 1999). This is either done because of normative considerations (a benevolent planner clearly would use the non distorting profit tax to the highest possible extent before levying distortionary factor taxes) or to be able to compare the results of the analysis to the standard results of the optimal taxation literature. The Diamond/Mirrlees production efficiency theorem, for instance, does not hold any more if there are pure profits that accrue to the private sector (Stiglitz/Dasgupta 1971, Mirrlees 1972).

Therefore, I add a tax on profits, $t_{\pi}$, to the model presented in Section 3. The value of $t_{\pi}$ is held constant during the tax reform. This is mainly done because the possibility of reducing profit taxes to rebate the revenue from an increased energy tax does not receive serious consideration in public discussion ${ }^{11}$. What I am and instead of cutting the wage tax rate, one would have to raise it (given that $t_{w}$ itself is Lafferefficient). In the following I therefore focus on efficient tax structures in the shaded area of Fig. 1 .

${ }^{11}$ This case is analysed in de Mooij/Bovenberg 1998b. Not surprisingly, it turns out that reducing 
mainly interested in is the effect of a given level of $t_{\pi}$ (which may have been fixed in advance by constitutional rules or by distributional considerations) on the labour market consequences of a revenue-neutral factor tax reform.

The introduction of the profit tax leads to the following changes. The tax revenue, expressed as the difference between total output and after-tax factor incomes, is now given by

$$
G=p Y-w L-q R-\left(1-t_{\pi}\right) \pi
$$

or, with profits as a fixed proportion of sales revenues

$$
G=\left(\kappa+\varepsilon^{-1} t_{\pi}\right) Y^{\kappa}-w L-q R
$$

Again focussing on the Cobb-Douglas-case where the net wage is constant and using the same factor demand functions as before, we have the following patial derivatives of the total tax revenue with respect to the factor tax rates

$$
\begin{aligned}
G_{t_{w}} & =\left[\left(\kappa+\varepsilon^{-1} t_{\pi}\right) \kappa p Y_{L}-w\right] L_{t_{w}}+\left[\left(\kappa+\varepsilon^{-1} t_{\pi}\right) \kappa p Y_{R}-q\right] R_{t_{w}} \\
G_{t_{q}} & =\left[\left(\kappa+\varepsilon^{-1} t_{\pi}\right) \kappa p Y_{L}-w\right] L_{t_{q}}+\left[\left(\kappa+\varepsilon^{-1} t_{\pi}\right) \kappa p Y_{R}-q\right] R_{t_{q}}
\end{aligned}
$$

This can be put in the same form as (4) and (5), but now the derived tax rates, $\tilde{t}_{w}$ and $\tilde{t}_{q}$, take on different values: $\tilde{t}_{i}=t_{i}-\left(1+t_{i}\right)\left(1-t_{\pi}\right) \varepsilon^{-1}(i=w, q)$. Thus the division of the region of tax reforms into subregions through the determination of the employment and production maximising tax rates proceeds as in Section 3. We would again end up exactly with Fig. 1 if we drew a $\tilde{t}_{w}-\tilde{t}_{q}$-diagram. However, in a $t_{w^{-}} t_{q^{-}}$-space, the effect of introducing a profit tax is to shift the whole system of curves towards the origin. In the extreme case of full profit taxation ${ }^{12}, t_{\pi} \longrightarrow 1$, a non distortionary tax is not beneficial, neither from a welfare nor from an employment point of view.

${ }^{12}$ Strictly speaking, the comparison of different profit tax rates is only possible for tax rates that 
the revenue maximum coincides with the origin (see Fig. 2) where both taxes on the factors of production equal zero. This means that the amount of gross-of-tax profits when there are no factor taxes equals the maximum attainable tax revenue. Raising a factor tax above zero would make profits fall to an extent which exceeds the revenue gain generated by the factor tax.

- Fig. 2 about here -

Comparing Fig. 1 and Fig. 2, one can see that the profit tax qualitatively affects the implications of a revenue-neutral tax reform in two ways:

1. First, consider a given tax structure. $\mathrm{A} t_{w^{-}} t_{q^{-}}$-combination that was efficient at low $t_{\pi}$ values can become inefficient at high $t_{\pi}$ values. This happens to all tax structures with two positive tax rates when $t_{\pi}$ approaches unity.

2. Second, consider a marginal ecological tax-reform identified by its starting point. This tax reform may generate employment gains for low $t_{\pi}$ values while employment losses result when the level of $t_{\pi}$ is high. Increasing $t_{\pi}$ means that LM shifts down so that tax structures change from below to above that line: The scope for employment enhancing ecological tax reforms shrinks ${ }^{13}$.

It is certainly problematic to apply the model under consideration for assessing tax reforms in the real world. The model tells us that ecological tax reforms will generate fall short of unity by at least an arbitrarily small amount. In the case of $t_{\pi}$ actually attaining unity, the bargaining outcome between firm and union is not determined any more. With a profit tax, the Nash product, $(1)$, contains $\left(1-t_{\pi}\right) \pi$ instead of $\pi$, and it would be zero for all $w$ when $t_{\pi}=1$. So Fig. 2 is to be understood as depicting the situation with $t_{\pi}$ below unity by an arbitrarily small amount.

${ }^{13}$ Again I restrict my attention to (Laffer-) efficient tax structures. Of course there might be further employment-enhancing tax reforms in the region where one or both tax(es) yield(s) negative marginal revenue(s). 
employment gains as long as the wage tax is higher than the energy tax. But at the same time it commits us to the view that total tax revenues are bounded from above by the amount of pure profits in a state of no taxation. Furthermore, it suggests that realistic values of the labour tax may well be Laffer-inefficient. Just for the sake of illustration, take the parameter values that de Mooij/Bovenberg (1998, p.29) chose for a "typical western european economy", interpret the share of the income to fixed capital, $w_{H}=.2$, as pure profits in the KSS model $(\varepsilon=5)$, and with $t_{\pi}=.33$, we arrive at the result that tax revenues are maximised with implicit factor taxes of 13.3 per cent on both factors. This is far below the tax rate, $t_{w}=1$ (exclusive tax rate), that de Mooij/Bovenberg take for their stylised economy.

As the next step, let us see how the outcome changes if we allow the net wage to vary.

\section{Variable wage with CES-production}

The analysis is more complicated once we turn from the Cobb-Douglas-case to the more general CES-case. The net wage, as the solution of the bargaining problem (1), then is a function of the factor tax rates, $w=w\left(t_{w}, t_{q}\right)$, with partial derivatives $w_{t_{w}}$ and $w_{t_{q}}$. Under CES production, the respective elasticities, $\eta_{w, t_{i}}=w_{t_{i}}\left(1+t_{i}\right) / w$ $(i=w, q)$, are just of the same absolute value but of opposite $\operatorname{sign}^{14}: \eta_{w, t_{l}}=-\eta_{w, t_{q}}$. This result can be used to derive expressions that allow to discriminate between regions with qualitatively different consequences of tax reforms analogously to Fig. 1 and 2.

\footnotetext{
${ }^{14}$ This is shown in KSS (1998). KSS (2001) departs slightly in that it combines a fixed net wage with CES production. The wage can therefore not be interpreted as a Nash-bargaining outcome.
} 
With a flexible wage, the partial derivatives of the tax revenue, (8) with respect to the factor tax rates change to

$$
\begin{aligned}
G_{t_{w}} & =\tilde{t}_{w} w L_{t_{w}}+\tilde{t}_{q} q K_{t_{w}}-L w_{t_{w}} \\
G_{t_{q}} & =\tilde{t}_{w} w L_{t_{q}}+\tilde{t}_{q} q K_{t_{q}}-L w_{t_{q}}
\end{aligned}
$$

where $\tilde{t}_{w}$ and $\tilde{t}_{q}$ are defined as in Section 4: $\tilde{t}_{i}=t_{i}-\left(1+t_{i}\right)\left(1-t_{\pi}\right) \varepsilon^{-1}(i=$ $w, q)$. Again, I use the expressions (6) and (7), which give the necessary conditions for a maximum of employment and output, respectively, to delimit areas of taxrate combinations with qualitatively distinct consequences when taken as point of departure of a tax reform. To characterise the employment maximising tax rates $\left(\max L\left(t_{w}, t_{q}\right)\right.$ s.t. $\left.G\left(t_{w}, t_{q}\right)=\bar{g}\right)$, we have

$$
\left[\left(\kappa+\varepsilon^{-1} t_{\pi}\right) \kappa p Y_{R}-q\right]\left(R_{t_{w}} L_{t_{q}}-R_{t_{q}} L_{t_{w}}\right)-L\left(w_{t_{w}} L_{t_{q}}-w_{t_{q}} L_{t_{w}}\right)=0 .
$$

In terms of elasticities this can be written as

$$
\begin{aligned}
{\left[\left(\kappa+\varepsilon^{-1} t_{\pi}\right) \kappa p Y_{R}-q\right] R\left(1+\eta_{w, t_{w}}\right)\left(\eta_{R, \tilde{w}} \eta_{L, \tilde{q}}-\eta_{R, \tilde{q}} \eta_{L, \tilde{w}}\right) } & \\
& -L w\left(\eta_{w, t_{w}} \eta_{L, \tilde{q}}-\eta_{w, t_{q}} \eta_{L, \tilde{w}}\right)=0
\end{aligned}
$$

Using $q=\left(1+t_{q}\right)^{-1} \kappa p Y_{R}$ (arising from the first order condition of profit maximising), $\eta_{R, \tilde{w}} \eta_{L, \tilde{q}}-\eta_{R, \tilde{q}} \eta_{L, \tilde{w}}=-\varepsilon \sigma, \eta_{L, \tilde{q}}+\eta_{L, \tilde{w}}=-\varepsilon$ (according to the values of the elasticities given in footnote 5$), s=\tilde{w} L /(\kappa p Y)$ and $\eta_{w, t_{w}}=-\eta_{w, t_{q}}$, we obtain the following expression for the employment maximising inclusive energy tax rate

$$
\frac{t_{q}}{1+t_{q}}=\left(1-t_{\pi}\right) \varepsilon^{-1}+\frac{s \eta_{w, t_{w}}}{(1-s)\left(1+\eta_{w, t_{w}}\right)\left(1+t_{w}\right) \sigma}
$$

In the Cobb-Douglas-case, with $\eta_{w, t_{w}}=0$, this is equivalent to $\tilde{t}_{q}=0$, as derived in Sections 3 and 4. Additionally to this "profit tax effect", there is a "wage effect" captured by the second term on the right-hand side of (12) and depending crucially 
on $\eta_{w, t_{w}}$. If a wage tax increases the net wage, this is detrimental to employment and a reason for a shift in taxation towards energy ${ }^{15}$.

Again, we find that the critical value of $t_{q}$ given in (12) is identical to the revenue maximising value of this tax. By maximising $G\left(t_{w}, t_{q}\right)$ in $t_{w}$ and $t_{q}$, which requires to set both (9) and (10) equal to zero, we arrive exactly at (12) together with a twin expression for $t_{w}$ :

$$
\frac{t_{w}}{1+t_{w}}=\left(1-t_{\pi}\right) \varepsilon^{-1}-\frac{\eta_{w, t_{w}}}{\left(1+\eta_{w, t_{w}}\right)\left(1+t_{w}\right) \sigma}
$$

Finally, the output maximising tax rates (solving $\max Y\left(L\left(t_{w}, t_{q}\right), R\left(t_{w}, t_{q}\right)\right)$ s.t. $G\left(t_{w}, t_{q}\right)=\bar{g}$, which leads to $\left.(7)\right)$, can be characterised by

$$
\frac{t_{q}}{1+t_{q}}-\frac{t_{w}}{1+t_{w}}=\frac{\eta_{w, t_{w}}}{\left(1+\eta_{w, t_{w}}\right)\left(1+t_{w}\right) \sigma}
$$

which holds, on consistency grounds, for the values of $t_{q}$ and $t_{w}$ given in (12) and (13).

Fig. 3 shows, analogously to Fig. 1 and 2, the sub-regions in the space of tax structures where tax reforms have qualitatively differing consequences. Fig. 3 contains the assumptions (i) that $\eta_{w, t_{w}}$ is negative as it is the case when the elasticity of substitution between labour and energy falls short of unity, and (ii) that $\eta_{w, t_{w}}$ as well as the factor shares are "relatively stable" during the tax reform so that their changes have no influence on the qualitative results. Fig. 3 shows the case of $t_{\pi}$ being arbitrarily close to unity $^{16}$; for $t_{\pi}<1$, we simply have to change the axes labels to $\tilde{t}_{w}$ and $\tilde{t}_{q}$ or shift all curves towards the upper right corner.

- Fig. 3 about here -

\footnotetext{
${ }^{15}$ This is in accordance with KSS's (1998) Proposition 4.

${ }^{16}$ Again, it is not possible to attain exactly $t_{\pi}=1$, for the reason given in footnote 10 .
} 
For the case of $t_{\pi} \longrightarrow 1$, Fig. 3 shows that even with a flexible wage there are no "efficient" tax structures with both tax rates positive. Although, in contrast to the case with Cobb-Douglas-production, it is now possible that positive values of $t_{w}$ become Laffer-efficient (the region in the first quadrant below $\bar{t}_{w}$ ), at the same time all these tax structures are characterised by a Laffer-inefficient $t_{q}$ (they do not form part of the shaded aera of efficient tax structures).

Analytically, it can be seen directly from equations (9) and (10) that there is no scope for efficient tax structures in the region of positive tax rates. As long as $w_{t_{w}}$ and $w_{t_{q}}$ are of opposite sign, (9) and (10) cannot simultaneously become positive (which defines Laffer-efficiency) for $\tilde{t}_{w}, \tilde{t}_{q}>0$. With $t_{\pi} \longrightarrow 1$, this also holds for the tax rates, $t_{w}$ and $t_{q}$, themselves.

Clearly, there would be no problem with the existence of efficient tax reforms if both $w_{t_{w}}$ and $w_{t_{q}}$ (or, equivalently, $\eta_{w, t_{q}}$ and $\eta_{w, t_{w}}$ ) were negative. As I will show in the following section, this is the natural outcome in a setting with a competitive labour market.

\section{Competitive labour market}

In the preceding sections we have seen that the labour market effects of a tax reform, in terms of the employment maximising tax on energy, crucially depend on the taxation of profits. By way of contrast, whether or not there is unemployment is of minor importance. This is shown in this section, which compares the the model of the previous sections with one in which labour markets are competitive.

To keep the analysis simple, labour supply on the competitive market is modelled as the result of the utility maximising decision of households with a quasi-linear 
utility function

$$
U=w L-v(L)
$$

where $v$ is the disutility of labour with both the first and the second derivative positive. Labour supply then is

$$
w=v^{\prime}(L)
$$

Combining this with the labour demand of the monopolistic firm (identical to that of the preceding sections), we can derive the following elasticities of the wage with respect to tax changes

$$
\begin{aligned}
\eta_{w, t_{w}} & =\frac{\eta_{L, \tilde{w}}}{\eta_{V}-\eta_{L, \tilde{w}}} \\
\eta_{w, t_{q}} & =\frac{\eta_{L, \tilde{q}}}{\eta_{V}-\eta_{L, \tilde{w}}}
\end{aligned}
$$

which are both negative, given $\eta_{L, \tilde{w}}, \eta_{L, \tilde{q}}<0$ for $\sigma<1$ and $\eta_{V}=w /\left(L v^{\prime \prime}\right)>0$. $\left(\eta_{V}\right.$ denotes the wage elasticity of labour supply, which equals the inverse elasticity of the marginal disutility of labour in the quasi-linear case.) As (11) is unaffected by the variation in the modelling of the labour market, we only have to substitute the new values of $\eta_{w, t_{w}}$ and $\eta_{w, t_{q}}$ for the old ones. The last term in (11) vanishes in this case so that we are again left with the expression for the employment maximising $t_{q}$ that was derived in the case of wage bargaining with Cobb-Douglas production:

$$
\frac{t_{q}}{1+t_{q}}=\left(1-t_{\pi}\right) \varepsilon^{-1}
$$

which holds irrespective of the elasticity of substitution. Thus, the only effect that is specific to the bargaining system is that which is associated with the second term of (12). It is also the only effect that depends on unemployment in the sense that it would disappear if the labour market cleared.

Again, we can compare the employment maximising tax rates with the highest 
Laffer-efficient ones. Tax revenue is now maximised by the tax rates

$$
\frac{t_{q}}{1+t_{q}}=\frac{t_{w}-\eta_{V}^{-1}}{1+t_{w}}=\left(1-t_{\pi}\right) \varepsilon^{-1} .
$$

This means:

1. As with wage-bargaining and unemployment, the employment maximising energy tax, given in (14), equals the budget maximising one.

2. Contrary to the case with wage-bargaining, the budget maximising $t_{w}$ now considerably exceeds the budget maximising $t_{q}$ : the difference is determined by the inverse elasticity of labour supply ${ }^{17}, \eta_{V}^{-1}$. In the figure of the space of tax structures (Fig 4 . with $t_{\pi}=1$ ) this translates into a rightward shift of the whole system of curves.

3. Consequently, the employment maximising $t_{q}$ is no longer necessarily higher than the employment maximising $t_{w}$. It is even likely that it will be just the opposite, at least as long as we are not too far away from the maximum budget.

- Fig. 4 about here -

\section{Conclusions}

The depiction of the range of "efficient" ecological tax reforms (when both taxes are Laffer-efficient) in Figs. 1 to 4 allows us to compare tax reform scenarios that differ in three dimensions: (i) profit tax versus no profit tax, (ii) rigid wage versus variable

\footnotetext{
${ }^{17}$ For a back-of-the-envelope calculation, take a wage elasticity of labour supply of 0.2 ; this means that $\eta_{V}^{-1}$ amounts to 5 , inducing wage tax rates in a range of (inclusively) 500 per cent or (exclusively) 83 per cent.
} 
wage, (iii) unemployment versus full employment. Thus, we can link possible effects of tax reforms to specific features of the model.

1. The key determinants of the scope for an employment enhancing ecological tax reform (in terms of the employment maximising tax on energy) are the level of the profit tax and the share of profits. This suggests the following interpretation of KSS's key result: The fact that a labour market dividend is reaped when the tax reform starts with a low energy tax rate is due to the presence of after-tax profits, not due to unemployment. If there were no after tax profits, the opportunity of rising employment by a tax reform of the type considered would vanish - if there were no unemployment, however, it would remain.

2. While the finding about the upper bound for an employment enhancing tax reform is fairly robust when we move from a labour market with unemployment to a competitive one ${ }^{18}$ (note again the striking equality of the employmentmaximising energy tax rates in Sections 4 and 6), the range of Laffer-efficient wage tax rates varies considerably. By the same token, any result about relative tax rates is likely to be sensitive to variations in the assumptions about the labour market. Results concerning the absolute level of critical tax rates might therefore be a better guideline for policy recommendations. This conclusion holds even if we remain sceptical about any specific tax rate generated by a model as simple as those of this paper.

3. The KSS-model commits us to the view that tax structures cannot be efficient

\footnotetext{
${ }^{18}$ The numerical calculations in Boeters (2000) suggest that this also holds for other types of unemployment. But, in principle, there are further effects that can influence the results, for example the replacement rate effects and incidence shifting effects of Bovenberg/van der Ploeg (1998a).
} 
if both factor tax rates are positive and profits are fully taxed away. Even in the more realistic case in which the tax on profits is between zero and unity, the scope for tax reforms is rather restricted. The calculation at the end of Section 4 led to budget maximising factor tax rates of 13 per cent on both factors. Taken at face value, this would mean that the real problem of most economies is that tax rates are Laffer-inefficient and could be cut together, instead of trading one tax for another.

4. The comparison of the KSS model with the case of a competitive labour market shows the crucial importance of wage flexibility for the overall scope for tax reforms. A plausible model of tax reforms under unemployment should at least share this feature with a full employment model: The net wage falls in response to an increase in both taxes involved in the reform.

The results of this paper suggest a redirection of research efforts when we analyse the labour market effects of ecological tax reforms. There is an evolution of the literature on taxation and unemployment during the last few years from simple models of unemployment to considerably more complex ones. The simple models are based on a fixed net wage, which is either due to wage bargaining with Cobb-Douglas production (KSS 1998) or to a special type of efficiency wage mechanism (Bovenberg/van der Ploeg 1998b). The more complex labour market models, by contrast, include both net and gross wage flexibility, e.g. the union model of Marsiliani/Renström (2000), the search model of Bovenberg/van der Ploeg (1998), or the efficiency wage model of Schneider (1997).

When we take the absolute value of the green tax rate - rather than its relative value as compared to the wage tax rate - as our main point of reference, the question of how exactly to model the labour market loses importance and profits enter the 
focus of attention. Using the back-of-the-envelope calculation from Section 4 for illustrative purposes, we can, in principle, express our labour market assessment of an ecological tax reform in the following, simple form: Given that profits are generated by a 20 per cent monopolistic mark-up on costs and are taxed at 33 per cent, a second dividend on the labour market can be reaped as long as the tax rate on energy is below 13 per cent - above that level, labour market effects will be negative. A refinement of this rough guess can be expected if we study profits more closely: their actual generation mechanism, magnitude and taxation - but not if we engage in a more and more detailed examination of the labour market.

\section{References}

[1] Boeters, Stefan (2000): Arbeitsmarktwirkungen einer budgetneutralen Reform der Besteuerung von Produktionsfaktoren (Labour market effekts of a revenueneutral factor tax reform), Frankfurt a.M.: Lang

[2] Boeters, Stefan; Schneider Kerstin (1999): Government versus union. The structure of optimal taxation in a unionized labor market, Finanzarchiv 56, 174-187

[3] Bovenberg, A. Lans; van der Ploeg, Frederick (1996): Optimal taxation, public goods and environmental policy with unvoluntary unemployment, Journal of Public Economics 62, 59-83

[4] Bovenberg, A. Lans; van der Ploeg, Frederick (1998a): Tax reform, structural unemployment and the environment, Scandinavian Journal of Economics 100, 593-610 
[5] Bovenberg, A. Lans; van der Ploeg, Frederick (1998b): Consequences of environmental tax reform for unemployment and welfare, Environmental and Resource Economics 12, 137-150

[6] de Mooij, Ruud A.; Bovenberg, A. Lans (1998): Environmental taxes, international capital mobility and inefficient tax systems: Tax burden vs. tax shifting, International Tax and Public Finance 5, 7-39

[7] Fuest, Clemens; Huber, Bernd (1999): Tax coordination and unemployment, International Tax and Public Finance 6, 7-26

[8] Koskela, Erkki; Schöb, Ronnie; Sinn, Hans-Werner (1998): Pollution, factor taxation and unemployment, International Tax and Public Finance 5, 379-396

[9] Koskela, Erkki; Schöb, Ronnie; Sinn, Hans-Werner (2001): Green tax reform and competitiveness, German Economic Review 2, 19-30

[10] Koskela, Erkki; Schöb, Ronnie (1998): Why governments should tax mobile capital in the presence of unemployment, Working Paper, University of Helsinki/University of Munich

[11] Marsiliani, Laura; Renström, Thomas I. (2000): Imperfect competition, labour market distortions and the double dividend hypothesis, Fondazione Eni Enrico Mattei, Nota di Lavoro 11/2000

[12] Michaelis, Jochen; Pflüger, Michael (2000): The impact of tax reforms on unemployment in a SMOPEC, Journal of Economics (Zeitschrift für Nationalökonomie $72,175-201$

[13] Mirrlees, James A. (1972): On producer taxation, Review of Economic Studies $39,105-111$ 
[14] Richter, Wolfram F.; Schneider, Kerstin (2001): Taxing mobile capital with labor market imperfections, International Tax and Public Finance, forthcoming

[15] Schneider, Kerstin (1997): Involuntary unemployment and environmental policy: The double dividend hypothesis, Scandinavian Journal of Economics, 99, $45-59$

[16] Scholz, Christian M. (1998): Involuntary unemployment and environmental policy: The double dividend hypothesis: A comment, Scandinavian Journal of Economics, 100, 663-664

[17] Stiglitz, Joseph; Dasgupta, Partha (1971): Differential taxation, public goods and economic efficiency, Review of Economic Studies 38, 151-174 


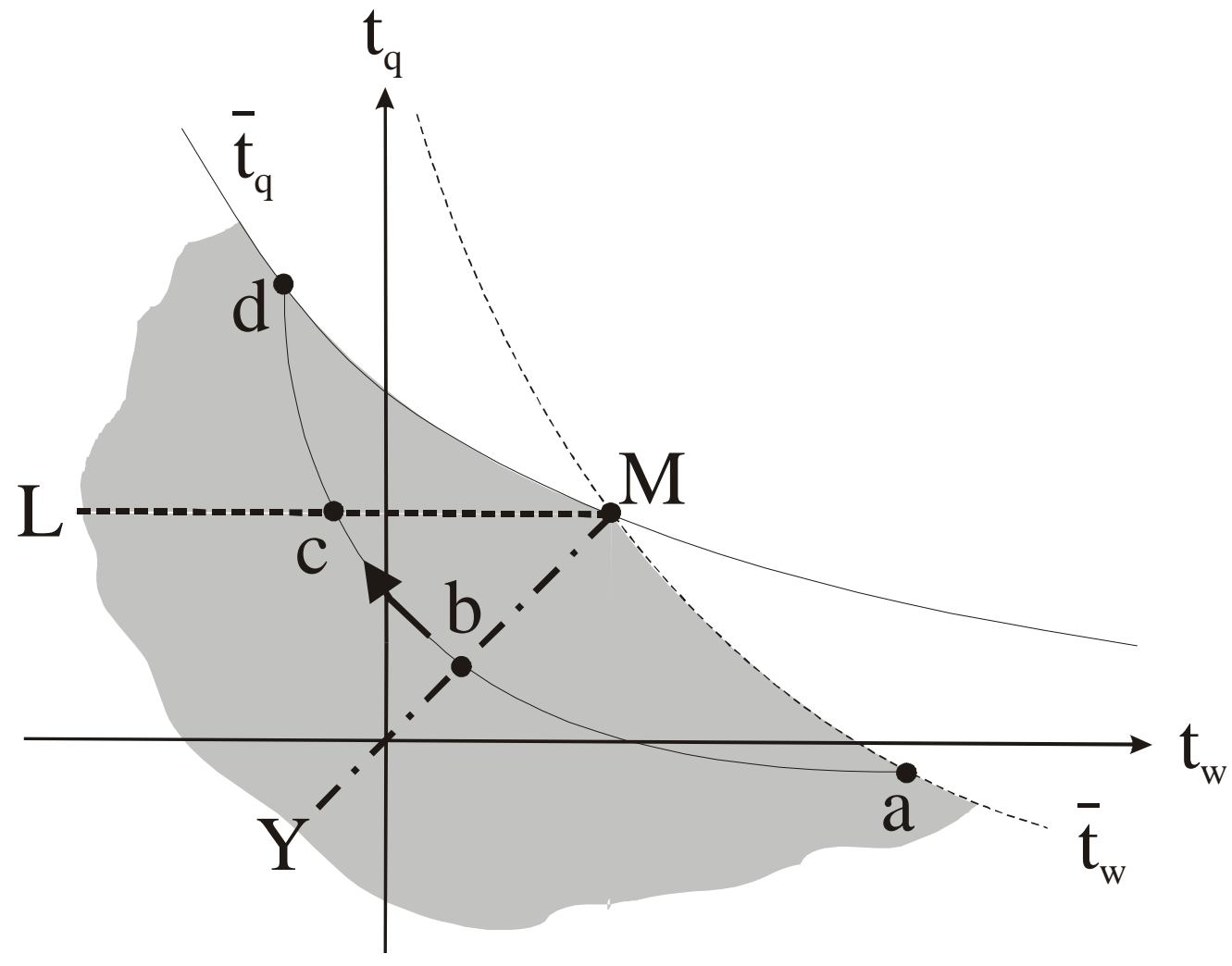

Fig. 1: Tax structures with $t_{\pi}<1$

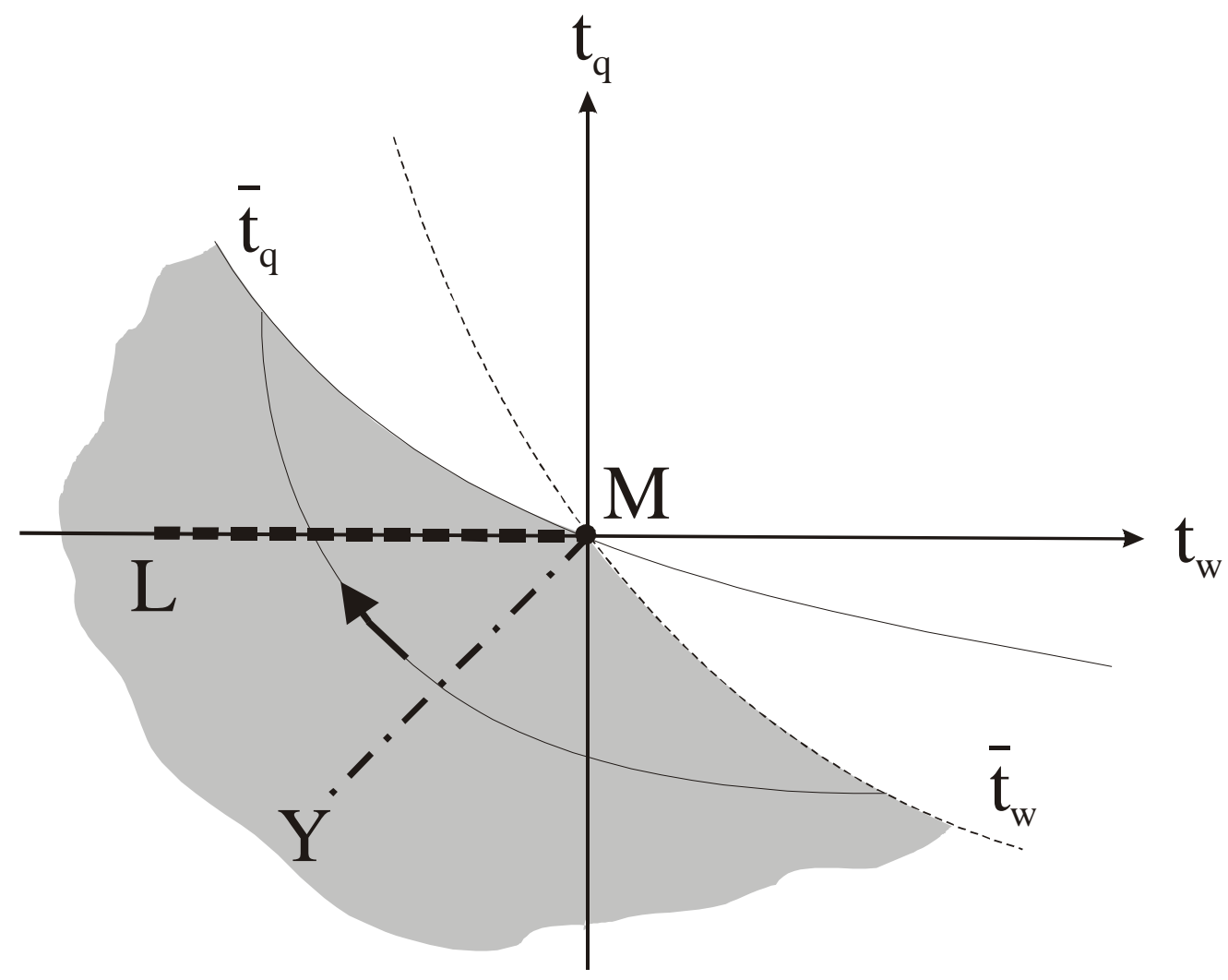

Fig. 2: Tax structures with $t_{\pi}=1$ 


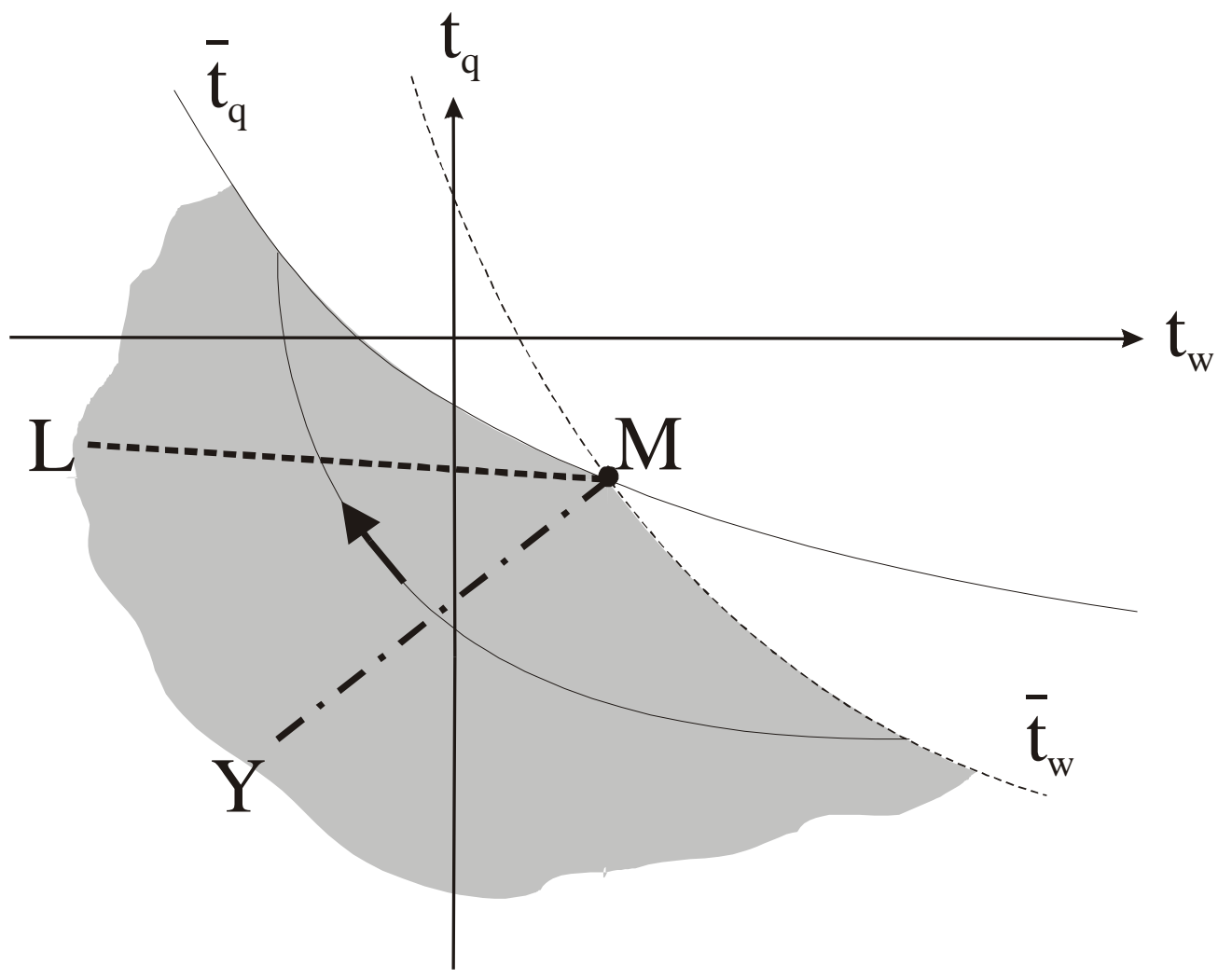

Fig. 3: Tax structures with $t_{\pi}=1$ and $\sigma<1$

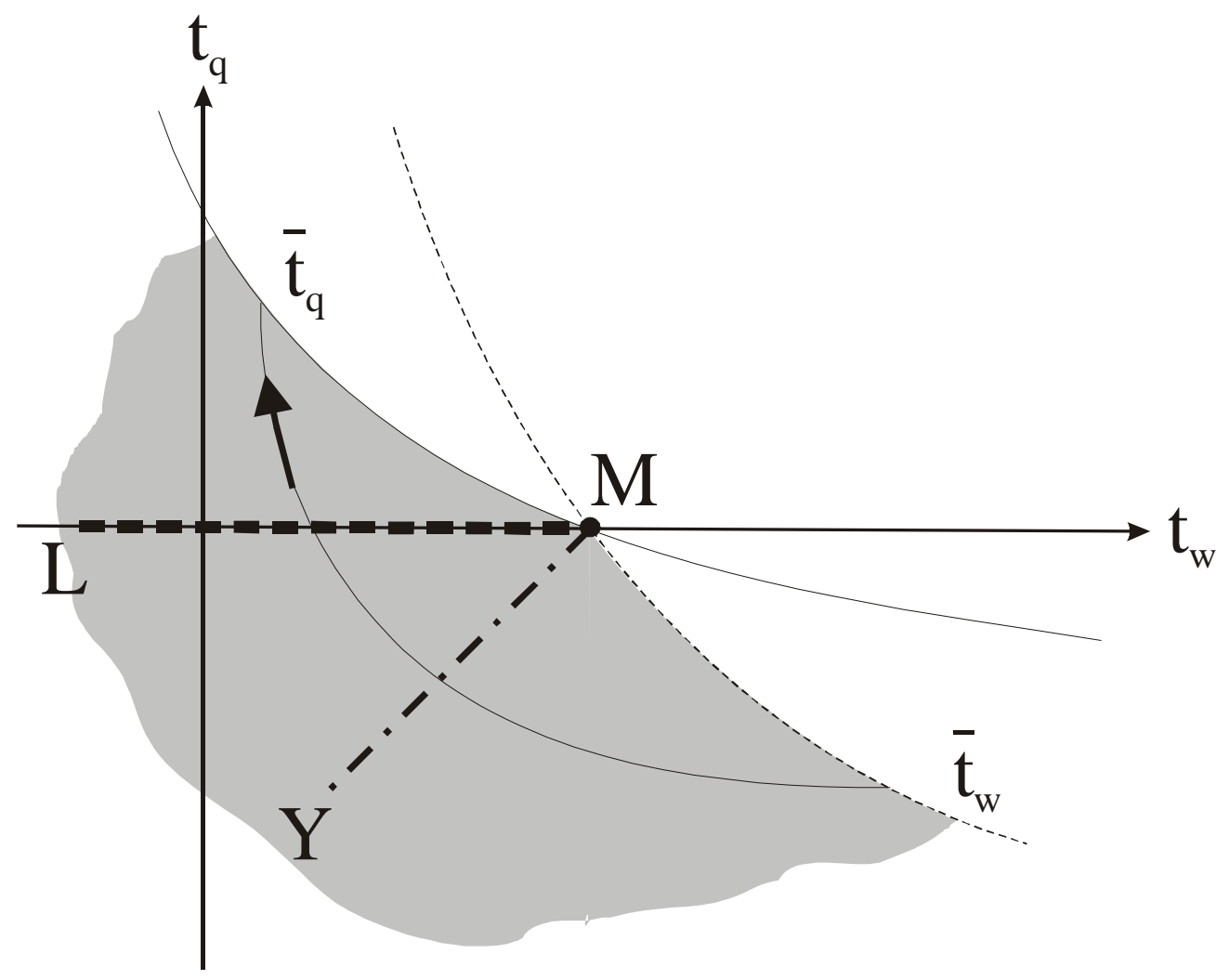

Fig. 4: Tax structures with $t_{\pi}=1$ (competitive labour market) 